\title{
Exploring workplace related health resources from a salutogenic perspective: Results from a focus group study among healthcare workers in Sweden
}

\author{
Åsa Bringsén ${ }^{\mathrm{a}, \mathrm{b}, *}$, H. Ingemar Andersson ${ }^{\mathrm{a}}$, Göran Ejlertsson ${ }^{\mathrm{a}}$ and Margareta Troein ${ }^{\mathrm{b}}$ \\ ${ }^{a}$ School of Health and Society, Kristianstad University, Kristianstad, Sweden \\ ${ }^{\mathrm{b}}$ Department of Clinical Sciences Malmö, Faculty of Medicine, Lund University, Lund, Sweden
}

Received 20 August 2009

Accepted 7 October 2010

\begin{abstract}
Objective: The aim of this study was to explore healthcare workers' opinions on workplace related health resources relevant to promotion of their health.

Participants: 16 registered nurses and 19 assistant nurses, from a medical emergency ward at a medium sized hospital in the south of Sweden, participated in the study.

Methods: Eight focus group interviews were conducted, the material was condensed and conventional qualitative content analysis was used to elicit and identify patterns in the expressed opinions of the participants.

Results: The analysis yielded four themes that were labelled the reward, the team, the mission and the context. An explanatory model was constructed consisting of concentric circles, with the reward at the core. The qualitative analysis also revealed two divergent patterns; some of the participants associated positive health with stability while others referred to flexibility.

Conclusions: The results from this study have contributed to the body of knowledge regarding salutogenic health indicators in the field of work and health research in particular as well as in health promotion in general. The findings show that individuals can have diverse responses to any given work situation, and this should be taken into account before implementation of salutogenic health promotion programs.
\end{abstract}

Keywords: Positive occupational health psychology, health promotion, subjective experiences, nursing

\section{Introduction}

Health development in general, as well as within the context of the workplace in particular, is a complex phenomenon that can be explored from either a pathogenic or a salutogenic perspective. Risk factors and disease are the centre of attention within the pathogenic perspective, while salutogenesis instead fo-

* Address for correspondence: Åsa Bringsén, School of Health and Society, Kristianstad University, 29188 Kristianstad, Sweden. Tel.: +4644204 098; Fax: +4644204 019; E-mail: asa. bringsen@hkr.se. cuses on resources for promotion of health in a positive sense [4]. A salutogenic perspective in health promotion is thus not considered equivalent to prevention of risk factors [4]. According to the World Health Organization (WHO) [38], health promotion is facilitated through supportive environments in society as a whole, and work is considered one important environmental source for peoples' health. A healthy and motivated workforce has been associated with social and economic welfare of the European Union [13].

Studies of work-related determinants of health from a salutogenic perspective are increasing but still rare. 
There is a growing emphasis on health promotion in public health [4] and organizational [36] research. One theory in particular that lends itself to the salutogenic model is sense of coherence (SOC) [30]. SOC is a health-related theory that provides an explanation for the role of stress in human functioning [3]. It links the individual's experience of comprehensibility, manageability and meaningfulness, in his or her life in general, to management of stress factors and improved health [3]. The link between an individual's positive experiences and health, characterized by the salutogenic perspective, is exemplified by the association between well-being and positive affect [12], Csikszentmihalyi's portrayal of the flow experience [10] and studies of salutogenic health indicators [8]. From a health promotion perspective, work should be safe, stimulating, satisfying and enjoyable in general [38], and should put positive experiences of the workers at the centre of attention. Thus within the field of health promotion, salutogenesis can also be incorporated into more general analytical perspectives of health development [4].

Health research in the workplace has traditionally taken a pathogenic perspective with adherence to a focus on the relationships between exposure to risks and ill health, morbidity or mortality $[31,36]$. From a pathogenic perspective, work in the health care sector in Sweden is characterized by high demands in relation to numerous social relationships and many responsibilities, limited room to control the work situation, indistinct leadership and constant changes without employee participation $[19,25]$. These characteristics can be linked to work-related dissatisfaction, emotional exhaustion and strain among registered nurses [17], and many nurses have expressed an intention to leave their nursing jobs [14]. This picture of healthcare work is recognised from other western countries, through studies made in the United States, Canada, England, Scotland and Germany [1].

To summarize, there is an expressed need to pay attention to the relationship between work and health from a salutogenic perspective $[13,31,36]$. The importance of focusing on work-related experiences, when describing health promotion and work, has been emphasized [13,38]. Finally, there is also a recognized need to improve the work-related experiences of healthcare workers $[1,19,25]$. A study for exploring the salutogenic relationship between work and health from a healthcare workers' point of view was therefore motivated and was conducted under the auspices of a workplace health promotion project in a hospital setting. The aim of this study was to explore healthcare workers' opinions on workplace characteristics or resources that were relevant to the promotion of their health.

\section{Participants and method}

\subsection{Study context}

This study was carried out within the framework of a hospital Workplace Health Promotion (WHP) project, where we tried to follow the guidelines for WHP in general. The project was launched at a hospital ward in the south of Sweden, during the winter of 2002-2003. WHP is considered to be a workplace development undertaking that aims for healthy employees in healthy organizations [13]. The WHP process focuses on improvement of the organization and the work environment, promotion of employees' participation in various workplace related areas, as well as encouragement of personal development related to work [13]. Guiding principles for the WHP process highlight the importance of 1) involving all staff (participation), 2) incorporating health-related reflection into all important organizational decision-making (integration), 3) utilizing a sustainable cyclic process that includes needs analysis, prioritization, planning, and implementing, as well as continuous evaluation, reflection and adjustment, and finally 4) focusing on both individually directed as well as organizational or environment-oriented strategies [13]. The cyclic description of WHP is in tune with Greenwood and Levin's [16] description of an action research process.

The ward, from which study participants would be recruited, was selected based on discussions within the hospital WHP projects reference group, which consisted of researchers from the University and representatives from the hospital. Criteria for selection of the setting took into account willingness to take part in the study and generalizability issues in relation to size, character, and distribution of professional groups, age and gender distribution, as well as sick leave statistics. Lack of interference from other health and employeerelated initiatives was also taken into account.

\subsection{Setting}

The study took place in a ward that was part of a care unit comprised of 14 other wards, reception areas, and so forth located in a medium-sized Swedish hospital. This medical emergency ward had a capacity to tend to 24 patients and specialized in gastroenterological and endocrinological disorders. Healthcare workers at the ward consisted of 17 registered nurses, 21 assistant nurses and a receptionist who was a trained assistant nurse and who also took part in the 
healthcare work. Administrative personnel that did not take part in the study were a head nurse and two secretaries. Doctors characteristically "visited" the ward during rounds and whenever they were needed at the ward throughout the rest of the day. The average age of the healthcare workers was 43; the assistant nurses were generally older and the registered nurses younger. During the day, the staff members were formally organized to work in pairs consisting of one registered nurse and one assistant nurse. It was, however, more common during everyday practice that the registered nurses carried out their tasks individually while the assistant nurses aided one another with their specific tasks. The schedules were individually set up and the employees had influence over their own work hours over five week periods, within a certain framework based on staffing requirements at the ward.

\subsection{Research process}

The hospital WHP project started with a focus group study, where the healthcare workers' opinions on workplace related factors that were relevant to the promotion of their health were explored. The WHP principle of participation formed the basis for inviting all health-care workers to take part in this study. The researcher presented the study during a staff meeting at the ward a few weeks before the interviews started. A poster with information about the study was then placed in the ward's staff room. Eight focus group interviews took place between November 2002 and February 2003. The interviews were conducted in Swedish. According to Morgan [28], focus group interviewing is a research technique in which data is collected through group interaction around a topic that has been decided by the researcher. Focus group interviewing is a medium for eliciting participants' opinions without the goal of reaching an agreement [28]. It was also important to make sure that all members from the target group had equal opportunities to participate and therefore the organization of the interviews was handled by the head nurse together with the researcher $(\AA \mathrm{B})$. Healthcare workers at the ward were given the opportunity to participate in the interviews during work and were informed by the head nurse a couple of days prior to the interviews. The criteria for selecting the participants of each group were based on a determination of who was scheduled to work at the time of the interviews as well as who had an interest to take part in the study. A total of 35 healthcare workers (out of 39), comprised of 16 registered nurses and 19 assistant nurses, decided to participate. The participants were distributed among the eight focus groups with 4-5 participants in each group.

Each focus group interview lasted approximately one hour and thirty minutes and was carried out in a conference room located on a different floor in the hospital. The interviews were audio-recorded. The researcher (ÅB) acted as a moderator and ensured that the intended direction of the discussion was maintained. The interviews were semi-structured and started with an overall question derived from the aim of the study. The question was, "What constitutes a health-promoting workplace?" The role of the moderator was then to ask follow-up questions and to request clarification and exemplification. Limited involvement by the moderator made it possible for the participants' opinions to evolve more freely. Subsequent to each interview, the researcher listened to the tape and made a written summary of the content, with added comments concerning the atmosphere and the character of the interaction in the focus group.

\subsection{Ethical issues}

The information given to the staff included the aim of the study and the focus of the interviews, and explained that the participation was voluntary and that the results would be handled with confidentiality. The researcher repeated the same information prior to each interview. Via organization by the head nurse, each healthcare worker at the ward was given the opportunity to participate, however in order to promote voluntary participation, he or she also had the opportunity to decline without the head nurse knowing about it. In order to facilitate an open climate during the interviews, we referred to participant confidentiality. However, complete confidentiality is not possible in focus group interviewing when the participants know each other and the researcher emphasized the importance of the participants' not sharing group member's contributions with others afterwards. The study was approved by the Research Ethics Committee of Lund University (LU141-03).

\subsection{Analysis}

The researcher (ÅB) conducted qualitative analysis of the information gathered from the interviews. Though content analysis can utilize a quantitative or qualitative approach $[5,15]$, the analysis in this study consisted of conventional qualitative content analysis 
in order to derive meaning from the interviews [18]. Conventional qualitative content analysis is considered useful when existing research is limited, as a means for allowing new insights to emerge from the data at hand without the use of predetermined categories [18]. The analysis focused on the latent content, which can be described as an interpretation of the underlying meaning of the text [15].

The researcher began the analysis by listening to the audio tapes and going through the written summaries. Five interviews were initially selected for the first step in condensation of the material based on their consistency with the aim of the study. These were transcribed verbatim by an external secretary. According to Graneheim and Lundman [15], condensation is a way to reduce the amount of material while maintaining the core content without jeopardizing the quality of the research process. Throughout the analysis, the researcher referred back to the remaining three interviews, but based on the principle of saturation these were not transcribed. Saturation was reached when there were no new insights emerging from the data [23]. The five selected interviews were considered to be representative of the material as a whole since the content of the non transcribed interviews supported the results emanating from the transcribed data.

The abstraction process used by the researcher can be recognized from a description of conventional qualitative analysis [18]. First, the transcriptions were read in order to get an overall impression. The next reading phase focused on identifying meaning units using initial or open coding. In the third step, the entire material was read again and the researcher wrote down her overall sense of what the data were about. This reading inspired the researcher to phrase some guiding questions for categorizing the codes as well as for interpreting and labeling the data.

- What workplace related resources did the participants consider to be health promoting?

- How can the workplace related resources be connected to the health of the healthcare workers?

- Is there any pattern of divergence in relation to the participating healthcare workers' opinions about the overall character of health-promoting work?

Codes that represented similar phenomena were then assembled into categories that were in line with the researcher's interpretation of the collective meaning of the connected units. The researcher continuously referred back and forth between the comprehensive written material and selected parts of the text in order to gain
Table 1

Themes and categories emanating from the analysis of the results

\begin{tabular}{ll}
\hline Theme & Category \\
\hline The reward & Joy \\
& Satisfaction \\
& Confirmation \\
& Learning \\
& Quality of private life \\
& Team parts \\
The team & Individual \\
& Team leader \\
The mission & Tasks \\
& Process \\
The context & Establishment \\
& Private life \\
\hline
\end{tabular}

a deeper understanding of the material. The categories derived from the analysis were then compiled into four different themes, based on their related content.

In the next step of the abstraction process, the perceived relationships between the different themes and categories were identified. An explanatory model was then constructed that was believed to represent these relationships, which were depicted as a set of concentric circles. The final step in the analysis focused on any divergent patterns that emerged from the data as evidenced by differences of opinions with regard to the overall characteristics of health-promoting work. In order to stimulate reflection and facilitate credibility of the research findings, the results from the analysis were discussed on several occasions among the authors and in a larger research group at the university. One of the co-authors (MT) also went through the transcriptions and cross-checked the analyzed results with the original data in order to enhance the credibility of the findings.

\section{Results}

The presentation of the findings is organized according to the three questions that guided the analysis. The identified workplace-related health resources, represented by the four themes and adherent categories, are presented first and are viewed in Table 1. These themes are labelled as: the reward, the team, the mission, and the context.

Findings related to each of the four themes is addressed and representative quotes from the interviews are inserted throughout. The numbers in brackets after each quote correspond to the fictitious code of the interview it was taken from. When more than one participant is active in the conversation, the different partici- 
pants are numbered 1, 2, 3, and so forth, and the moderator's presence is marked with an " $\mathrm{M}$ " in brackets.

The second part of the results section consists of a discussion of the proposed relationship between the different themes and their categories and the participants' health. Finally, the last section reports the results of analysis of the divergent patterns that emerged from participants' contradictory opinions about an overall character of health-promoting work.

\subsection{Workplace related health resources}

Each theme describes a different health promoting workplace characteristic or resource described by the participants. The categories under each theme represent a specific type of positive and/or meaningful health promoting experience among the participating healthcare workers.

\subsubsection{The reward}

This theme was characterized by five categories of positive and meaningful experiences that were health promoting according to the participating healthcare workers. These were: joy, satisfaction, confirmation, learning and quality of private life. Feelings of joy were linked to the experience of being part of something greater, for example a group or fellowship, at the workplace.

"And of course it's important that there's a good atmosphere. It's more fun to come to work and so 'cause you're pals at work and you see them and it's nice to talk... and yeah, you so to speak hang out even though you're at work." (14)

Apart from the social rewards concerning fellow coworkers, feelings of joy were also linked to the everyday work of helping patients in need. Feelings of satisfaction were also often mentioned in the focus groups. It seemed that satisfaction was important when it was linked to a feeling of being in control and able to handle various situations at work.

“That you're happy with what you've accomplished, that you've done something good. That you manage your job [...], that sense of 'I'm not going to manage this'-feeling is no fun.” (14)

Satisfaction was also experienced as a result of selfreflection on one's work performance after having finished work for the day. The feelings of satisfaction were, at times, linked to helping the patients, regardless of whether the healthcare worker received a response or acknowledgment. Satisfaction was, although, almost always experienced in situations where the patients expressed their gratitude for the care they were given by the staff.

"1 - First of all, I mean, you like working with people, you get a lot back from them - the patients. ( $\mathrm{M}-$ How is this expressed?)

1 - Gratitude, jokingly many times, I reckon. There you can get a lot back that you can thrive on for another hour.

( $\mathrm{M}$ - How does it feel when you experience that?)

1 - It feels really good.

2 - I mean, praise is great, you're never really too old for that." (12)

A positive reaction from the patients led to an experience of confirmation. It was from the patients that the healthcare workers had the opportunity to receive an immediate verification and acknowledgement on the quality of their work performance. Confirmation was also experienced when co-workers turned to one another for support in various situations.

("M - What is it about your co-workers that is positive?)

Above all, it is that you can reflect on what you do and sort of, did I do it right? And how would you have done it? That you can discuss things about the way you work." (10)

Another rewarding and health promoting experience was learning. Learning was primarily associated with co-workers and patients. Situations in everyday work that were affirming often resulted in reflection, learning, acquisition of new knowledge, and sometimes in changed practices. New members of the staff particularly emphasized the importance of learning from their interactions with co-workers in everyday situations at work. In contrast, older members of the staff emphasized the need for a more formal process to promote development of skills and competence, such as attending training courses. They also stressed the importance of physically leaving the ward on these occasions.

"You can need a little ... it's like getting an injection of vitamins if you get the chance of actually going away to do something. It gives you a kind of adrenaline kick to go to a lecture/presentation, or if you have taken a class of some sort." (14)

The experience of functioning as a resource to help others develop skills and acquire new knowledge was also considered to be health promoting. Learning at work did not always result in an improvement of work qualifications, but could be related to the development of life skills in general. 
"She didn't know how to make coffee, for example, so I just like 'come on, I'm going to help you make coffee 'cause that's something you need to know how to do, doggone it. It's just the way it is. It's pretty nice when you feel like you too have grown when you've been able to teach these girls something." (11)

The opinions varied among the participants with regard to the perceived link between learning and health promotion, particularly if it called for reflection and changes in practice. On the one hand, some of them were in favor of learning to a great extent, while others stressed the importance of a predictable work situation that demanded less learning, reflection and changes in practice.

Quality of private life was another rewarding health experience that the participants considered valuable. Quality of private life was positively affected through wages, vacation periods, and the ability to influence work hours, as well as the ability to keep thoughts about work at bay when participants were not working. An influence on working hours was handled quite differently among the individual participants. Some arranged their work hours depending on, for instance, the family situation and leisure activities. "That you can, sort of, control your own hours, sometimes you want to work more and sometimes less." (10) Others kept the traditional schedule and were reluctant to make adjustments or fully utilize the allowed flexibility.

"To the extent that I'm able to, I want to have scheduled working hours. None of this dilly-dallying about 'you're working this day and you're working that day' and 'can you change your weekends? pick another weekend'. I want continuity in my schedule just like it's been before. Period!" (13)

\subsubsection{The team}

The entire group of healthcare staff, together with the head nurse, were considered, by the participants, to represent the team. The doctors were included as part of the team when they were present and took part in the health-care work at the ward. Belonging to a collective was found to be meaningful in a general sense.

“There should be a sense of a 'we' feeling, sort of like a team ... not that you're one by one but an entire group." (12)

The team could also serve as a resource for internal communication and collaboration, which were found useful to the participating healthcare workers in their everyday practice at the ward. On various occasions, the participants emphasized the importance of the experience of working with the team parts that were made up of various smaller groups or pairing of staff members having the same or different professions. The participants stated that their different professions complemented each other well and resulted in improved quality in their work performance thanks to their combined efforts.

"Well, if you're headed toward that, for example, that you are to improve the nursing care, then both the assistant nurse and the registered nurse collaborate "cause you really see different things." (14)

The two professional groups of assistant nurses and registered nurses were portrayed quite differently. The assistant nurses at the ward were described as being a rather tight and homogeneous group. They knew each other very well since many of them had been working together at the same ward for several years. Some of the assistant nurses always wanted to work with the same co-workers and were in favor of a predictable work situation in general. They considered the characteristics of their group to be a strength and support in terms of health promotion, but they could also recognize this being a problem to others at the ward on various occasions.

" 1 - We are set in our ways.

(M - How do you mean?)

2 - All of that isn't really true, is it? 'Cause afterwards, once it's been carried out, it turned out to be good anyway, no? So perhaps we're a little bit stubborn." (13)

In contrast, the relationships among the registered nurses were described as being less intimate and familiar, but they served as professional support to one another during working hours. The registered nurses were more in favor of working with different co-workers from time to time.

Furthermore, the quality of work was linked to being able to trust the performance of the individual and was considered to be an important aspect of the entire group.

"1 - That you can trust your co-workers, sort of, and that you're able to hand over something like that ... and that it's being done.

2 - So you don't have to double-check.

1 - Yes, exactly." (10)

The team leader was also considered being a part of the team, by the participants. The participants talked about the necessity of having a leader that cared about them. 
" 1 - Yes, they should care about their staff.

2 - They should care about how we are and how we're doing in terms of the work, I mean.

3 - That you feel appreciation from your boss." (10)

The opinions regarding the characteristics of a health promoting leader varied. Some were in favor of an authoritarian leader, while others wanted the leader to be more of a friend. Sometimes, the participants talked about the leader being the team's representative, whereas there were situations when the definition of a healthpromoting leader was equivalent to the caring role of a mother.

\subsubsection{The mission}

The team was responsible for carrying out the mission that was linked to the objectives of the ward. The mission was characterized by the experience of the two categories tasks and processes. Some of the tasks had to do with the immediate caring of the patients in a practical sense, whereas others, such as administrative tasks, were more indirectly linked to the patients. The nearer the task was to the patients the more meaningful it was to the participants.

"If I am to be responsible for a certain number of patients, it's necessary, in order for me to get satisfaction in my job as a registered nurse, that I have a dialogue with the patients./. . ./Otherwise I will feel stressed ... it feels like I haven't met ... I don't get a feel for the patients then." (14)

Participants did portray some tasks, considered to have a weak link to immediate patient care, in a positive way. These consisted of development work or specific areas of responsibility in which they served as a resource, helped to overcome challenges, facilitated influence, or contributed to variety in their everyday work on the ward.

"I think that's good the way we have it today and that we have different areas of work, the schedule, etc." (12)

It was important to the health-care workers to feel that the tasks they carried out were of a high quality in order for them to be content with their work performance after finishing their work for the day. The variety of situations that they faced each day at the ward needed to be manageable and linked to a feeling of being in control. The participants' work qualifications were health promoting resources that contributed to the experience of manageability and of being in control. However, these experiences were more often linked to the management and the work process of the team.
"Yes, in parts it is organizationally decided as to how you collaborate at a ward. That is very important, so that there aren't a lot of unnecessary running around and such." (10)

The process represented the experience of the way the work was organized. Some of the participants emphasized the importance of the work running smoothly when they carried out their tasks. Work running smoothly was considered to be dependent on health promoting resources such as routines, schedules, the physical environment, workload, leadership and collaboration, as well as communication between the different individuals and parts of the team. Whereas some of the participants generally wanted the work to run smoothly and without effort, others wanted to experience challenges now and again. The ability to handle challenging situations could be improved by learning from communicating with different team members from time to time. Having a schedule and a process that facilitated working with different members of the team was thus considered a valuable resource. The participants that were in favor of efficient and effortless work always wanted to work with the same team members, so they knew what the others would do, and how they would do it, without having to communicate more than necessary during the work.

\subsubsection{The context}

The experience of the establishment was one of the categories that represented the context theme. The general objectives of the hospital, and the ward in particular, controlled some of the aspects of how the work was organized at the ward. The participants often talked about the needs of the patients and the ward's relationship to other parts and areas of the establishment.

“Then there's also a lot you say in passing when doing odd little tasks that make it work, 'cause if that doesn't work there isn't any flow. It could be anything from $\mathrm{x}$-rays to contacting the municipality or looking for referrals." (10)

Some of the routines were, for instance, considered predetermined by the contextual factors of the establishment, and were thus often taken for granted by the participants. Even though the participating healthcare workers were not able to influence these routines, they served as health promoting resources when they presented a predictable structure for and support of the staff member's everyday work at the ward. 


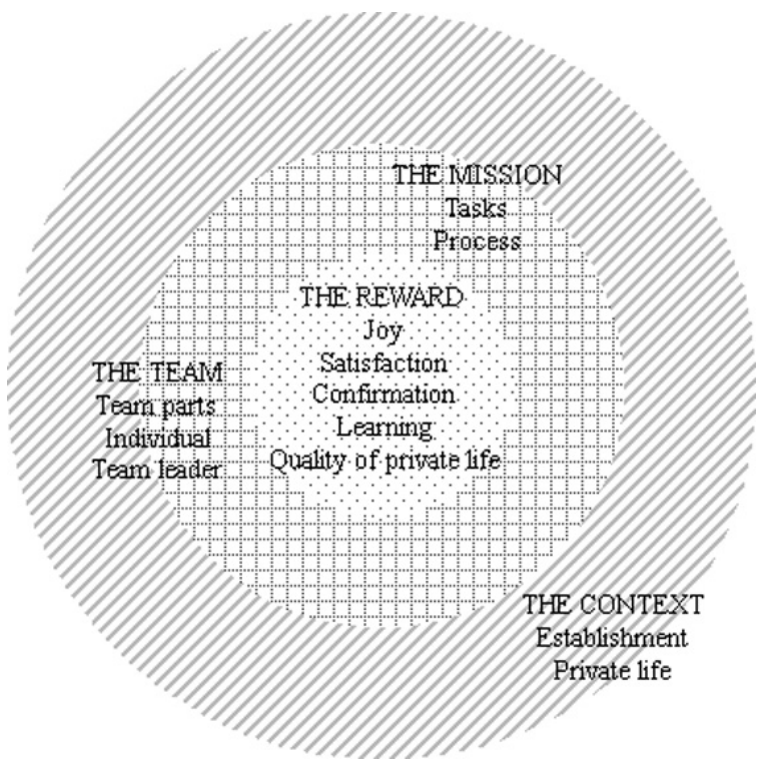

Fig. 1. Circular framework representing the relationship between workplace related resources and health among health-care workers.

"Our work is really entirely based on work routines, so if one falls away, then seriously, the rest of the day will turn into chaos." (12)

Another contextual category was the experience of private life. The participants emphasized the dialectic link between their private life and themselves as individuals in their work life. If they had a good day at work, they were better equipped to deal with various situations in their private life, and vice versa.

\subsection{Workplace related resources and health}

Interpretation of the relationships between the different themes and their associated categories led to a proposed model consisting of concentric circles that represented a consolidated picture of health promoting workplace characteristics, resources and experiences. This model is depicted in Fig. 1. Note that the theme of the reward is in the central position, the theme of the context is in the outer position, and the remaining themes of the mission and the team are in between.

The placement of the themes and associated categories in this model was based on how they were represented in the data. The reward, was placed in the centre of the model because this theme was interpreted by the researchers as being at the core of the participating healthcare workers' experience of what constitutes a health promoting workplace. The participants saw the team as being responsible for carrying out the mission, and both were considered to be dependent on the contextual characteristics of the establishment and private life. The results showed that the levels were connected by a mutually influential relationship.

\subsection{Divergent responses among the participants}

When the researchers looked at the overall pattern of participant responses, two rather different pictures emerged. Some of the participants were in favor of work that was characterized by variety, challenges, reflection, learning, development work and their work being adjusted to them as individuals. In contrast, others emphasized the importance of stability, predictability, "peace and quiet" and an adjustment of ones life, in general, to the framework of their work. The type of work presented in the first picture was labelled as flexible while the other was labelled as stable. Supporters of both patterns wanted to have control over their work situations, and yet their opinions of how to achieve this control varied.

\section{Discussion}

The aim of this study was to explore healthcare workers' opinions on workplace related factors that are relevant to the promotion of their health. These were called workplace related health promoting characteristics or resources.

\subsection{Themes and categories}

When comparing the different health resources that have emerged in this study, there are some similarities to other studies and theories that focus on workplace related health resources. The importance of experiencing reward can be recognized from both the positive affects of the concept of well-being [12] and the work-related effort-reward imbalance model [34]. It is reasonable to make the reward theme the core of a health-promoting workplace, mainly due to its motivational function for the participating health-care workers. The importance of internal or intrinsic motivational resources is also emphasized in, for instance, the component of meaningfulness [3], the work of Nilsson et al. [29] and Csikszentmihalyi [10].

In this study, meaningfulness as described by Antonovsky [3], can be related to the social and supportive function of co-workers that represents the team and the participants' description of patient-related 
tasks that emanate from the mission. The function of social support may, however, also be linked to Antonovsky's [3] concept of manageability and shares similarities with the support dimension in the demandcontrol-support model [21]. The positive link between social support at work and employees' health has been described in numerous studies [2,3,21,26,30].

Even though the results show that there are many different health resources available in this type of workplace, the target group is on a national level overrepresented in the statistics of sick leave [35]. One explanation for this could be linked to the determinants of health being somewhat different than the determinants of ill health [27] as well as the identified, slightly different, patterns of determinants that promote excellent work ability and prevent poor work ability [24]. From this standpoint, a workplace can be characterized by health resources from a salutogenic perspective, and at the same time risk factors for disease. The broadness and complexity of the determinants of sick leave, in general, are thus probably somewhat different from those of a health-promoting workplace. In our previous work, healthcare workers reported symptoms of stress together with a perception that their health was pretty good [2]. One explanation for this may be linked to the mutual influential relationship between a health-promoting workplace and the private life that was representing the context theme.

\subsection{Concentric circle model}

The analysis also resulted in the creation of a concentric circle model that represents the participants' collective picture of salutogenic relationships between workplace related factors and health. This model of health promoting resources shares similarities with the European Community Health Promotion Indicator (EUHPID) Development Model. The EUHPID development model divides the determinants of positive health into environmental and individual resources, which are related through a mutual influential relationship, and could serve as target factors for public health intervention in the field of health promotion [4]. Similar to Bauer et al. [4], we placed the context-related theme in the outer circle. According to our analysis, the context is partly represented by private life. Private life can, however, also be considered an individualistic determinant of health. From our interpretation, the health resources that represent the mission and the team can be considered environmental factors, which are dependent on the context of the establishment. Similar to the
EUHPID development model [4], we placed the most individualistic and intrinsic theme in the centre of our framework. Focusing on work-related positive experiences in particular is in tune with the WHO description of health promotion [38] and can be related to other circumstances where positive experiences have been related to health in a more general sense $[8,10,12]$.

\subsection{The divergent responses}

The pattern of divergent responses, namely the identification of stable versus flexible work as being health promoting, is of great interest with regard to the implications for WHP practice in general. The emergence of the two different pictures may be a result of the individuals actually having different salutogenic work related health requirements. This has been suggested by studies based on theoretical concepts such as learned resourcefulness [33], mastery and self-esteem [6], hardiness [20] and SOC [3]. The presence of divergent health related needs implies that staff members can experience both positive and negative health impacts if implementation of the WHP promotes flexible over stable work or vice versa. The risk of WHP projects resulting in both positive and negative effects has previously been discussed [7] and the complexity of desirable and undesirable characteristics in relation to psychological determinants of health can be recognized from the work of Robbins, Spence and Clark [32]. Awareness and action might be needed in order to match employees according to their preference for flexible or stable work when implementing change within the framework of the hospital WHP project.

On the other hand, the link between the concept of flexible work and theories of flow [10], active work [22] and Sense of Coherence (SOC) [3] suggests that workplace health promotion initiatives based on flexible work have a better chance of actually improving the employees' health. Stable work may perhaps be more tolerable among some of the team participants at this particular ward whether it fits their salutogenic health related needs or not. According to Csikszentmihalyi [11], some people tend to judge their needs through social conventions rather than through an awareness of their genuine feelings. Csikzentmihalyi [11] relates this to people preferring other things than work, despite reporting that they have more positive feelings at work. According to Cramer, van der Heijden and Jonker [9], a company-specific meaning of a concept is created when project-related activities that make a contribution to the workplace are reflected in a broader sense. From 
this standpoint, the differences in opinions among the participants may diminish as the hospital WHP project is implemented and evaluated.

Another conclusion may be that the two combined pictures serve as a valuable health-promoting mixture, with the possibility that positive experiences among all participants will result on some occasions. Perhaps people, in a general sense, need to have some negative work related experiences from time to time in order to appreciate the positive ones more. This could be linked to some of the theories of balance in relation to work. Siegrist [34] proposes that work should be characterized by a balance between effort and reward. Effort represents the negative experience of cost while the reward is the positive benefit gained in return [34]. Active work is also characterized by a balance between positive and negative experiences [22]. Demands represent the negative experiences and control includes the positive ones in this theory [22]. The positive experience should be prevalent, since risk factors have a stronger association to ill health than the salutogenic health-related determinants have on excellent health [27]. This brings us back to the problematic situation where the supporters of two diverse work characteristics need to have prevailing positive experiences. In order to be able to explore the issue of diversity more profoundly, further research is required.

\subsection{Methodological considerations}

The researchers wanted to contribute to the identification of salutogenic indicators in the field of public health and health promotion in general, while at the same time facilitating an improvement of the workplace related experience of healthcare workers via a hospital WHP project. Combining research with practical application and program development is a form of action research [16]. Combining WHP practice with research is an interesting as well as challenging venture, where the needs and possibilities within a framework of progressive problem solving meet the demands in relation to quality criteria in research.

The decision to focus on healthcare workers at only one ward might be questioned from a research perspective. However, it is the nature of exploratory qualitative research to take a narrower focus in order to obtain rich and in-depth contextual data. This approach enhanced our understanding of the views of healthcare workers within the framework of the hospital WHP project. The identified workplace related health promoting themes and categories were useful at the participatory planning and prioritization phase of the project. The acknowledged pattern of divergent responses also functioned as a resource for the project. An awareness of differences in opinions among the participants at an early stage of the project made it possible to adapt the process to focus on communication, tolerance and management of these differences.

The study produced a comprehensive body of qualitative data in which some differences concerning the perceived overall character of the work were reflected. These variations were sometimes linked to individual focus groups, but for the most part the different opinions about a health promoting workplace appeared in the same interview. Our conclusion is therefore that the variations are the result of the participants actually having different opinions, and that they felt secure enough to share them with the others in the focus groups.

The capability to reflect upon the results of the interviews in relation to the group climate and interaction patterns would have been greater had an assistant observer been present. An assistant observer could, for instance, have kept better track of who said what during the interviews as well as of nonverbal expressions and other contextual factors. These observations might have facilitated a more in-depth explanation regarding the two divergent response patterns among the participants in the different groups. These observations might have also helped to explain why some of the interviews proceeded more smoothly and were more comprehensive with regards to the aim of the study, than others. Unfortunately, the resources within the WHP project were limited. From a pragmatic point of view, an assistant observer was therefore not prioritized, and the moderator tried to capture the specific characteristics of the different groups in notes recorded following each interview.

The condensation of the tape-based qualitative data was considered subsequent to reflection on some of the interviews being similar in content. Five interviews were selected based on their comprehensiveness with regard to the aim of the study. Going back to the non-transcribed interviews throughout the analysis has limited the risk of missing something important and the material in these interviews supports the analysed results from the transcribed data. In order to enable the reader to judge whether the results are credible and transferable to other settings, we have tried to describe the research context, setting and process as thoroughly as possible. 


\subsection{Conclusions}

This study resulted in four main themes with workplace related health resources. The salutogenic relationships between the themes and the participants' health resulted in a concentric circle model where the core was represented by the health-care workers' individual experience of reward. An important finding was the diversity among the participants. Some were in favor of work being characterized by flexibility, while others instead emphasized the importance of stability. The salutogenic focus, as well as the identified patterns of diversity among the participants in our study, is considered a useful complement to the ordinary pathogenic-oriented research in the field of public health and health promotion. The identified work-related health resources and the circular framework can function as a supportive frame of reference for WHP initiatives aiming for a salutogenic perspective. The identified pattern of diversity highlights the importance of always exploring the needs of the particular workers at hand, in order to facilitate positive effects from WHP initiatives. Further research is required for an opportunity to more profoundly explore and study similarities as well as diversities in relation to workplace related health resources and workers' health from a salutogenic perspective.

\section{Acknowledgements}

This study was supported by funding from the Swedish Savings Bank Foundation and Krinova Science Park, Kristianstad, Sweden.

\section{References}

[1] L. Aiken, S. Clarke, D. Sloane, J. Sochalski, R. Busse, H. Clarke, P. Giovannetti, J. Hunt, A. M. Rafferty, and J. Shamian, Nurses' Reports On Hospital Care In Five Countries, Health Affairs. 20 (2001), 43-53.

[2] H. I. Andersson, Å. Bringsén and G. Ejlertsson, Pain symptoms reported by Swedish health-care workers, Abstract. Pain in Europe IV, $4^{\text {th }}$ Congress of EFIC, the European Federation of the International Association for the study of Pain Chapters, Czech Republic, Prague, 2003.

[3] A. Antonovsky, Unravelling the Mystery of Health: How People Manage Stress and Stay Well, Jossey-Bass Publishers, San Fransisco, 1987.

[4] G. Bauer, J. K. Davies and J. Pelikan, The EUHPID Health Development Model for the classification of public health indicators, Health Prom Int. 21 (2006), 153-159.

[5] B. L. Berg, Qualitative research methods for the social sciences, Pearson Education Inc, Boston, 2004.
[6] P. Bovier, E. Chamot and T. Perneger, Perceived stress, internal resources, and social support as determinants of mental health among young adults, Qual Life Res. 13 (2004), 161-170.

[7] Å. Bringsén, I. H. Andersson and G. Ejlertsson, Workplace health promotion programs change employees' health for the worse, Abstract. The 18th Nordic Conference in Social Medicine and Public Health. Helsinki, Finland, 2007.

[8] Å. Bringsén, I. H. Andersson and G. Ejlertsson, Development and Quality Analysis of the Salutogenic Health Indicator Scale (SHIS), Scand J Public Health. 37 (2009), 13-19.

[9] J. Cramer, A. van der Heijden and J. Jonker, Corporate social responsibility: Making sense through thinking and acting, Business Ethics: A European Review. 4 (2006), 380-389.

[10] M. Csikszentmihalyi, Beyond boredom and anxiety. Experiencing flow in work and play, Jossey-Bass Publishers, San Fransisco, 1975.

[11] M. Csikszentmihalyi and J. LeFevre, Optimal experience in work and leisure, J Pers Soc Psychol. 5 (1989), 815-822.

[12] E. Diener, E. M. Suh, R. E. Lucas and H. L. Smith, Subjective well-being: Three decades of progress, Psychol Bull. 125 (1999), 276-302.

[13] European Network for Workplace Health Promotion. Luxembourg Declaration on Workplace Health Promotion in the European Union 1997, http://www.enwhp.org, [090122].

[14] A. Gardulf, I-L. Söderström, M-L. Orton, L. Erikson, B. Arnetz and G. Nordström, Why do nurses at a university hospital want to quit their jobs? J Nurs Manag. 13 (2008), 329-337.

[15] U. H. Graneheim and B. Lundman, Qualitative content analysis in nursing research: Concepts, procedures and measures to achieve trustworthiness, Nurse Educ Today. 24 (2003), 105112.

[16] D. J. Greenwood and M. Levin, Introduction to Action Research. Social Research for Social Change, Sage publications, California, 1998.

[17] K. Hallin and E. Danielsson, Registered nurses' experiences of daily work, a balance between strain and stimulation: A qualitative study, Int J Nurs Stud. 44 (2007), 1221-1230.

[18] H-F. Hsieh and S. E. Shannon, Three approaches to qualitative content analysis, Qual Health Res. 19 (2005), 1277-1288.

[19] H. Harder, E. Svärd, A. Wigfors and K. Hedén, Stress och belastning $i$ vård och omsorg, [In Swedish] (Stress and workload in health- and elderly care), Arbetarskyddsstyrelsen (2000:8), Stockholm, http://www.arbsky.se [090120].

[20] M. Harrisson, C. Loiselle, A. Duquette and S. Semenic, Hardiness, work support and psychological distress among nursing assistants and registered nurses in Quebec, $J$ Adv Nurs. 38 (2002), 584-591.

[21] J. Johnson and E. Hall, Job Strain, Work Place Social Support and Cardiovascular Disease: A Cross-Sectional Study of a Random Sample of the Swedish Working Population, Am J Public Health. 78 (1988), 1336-1342.

[22] R. Karasek and T. Theorell, Healthy work: Stress, productivity, and the reconstruction of working life, Basic Books, New York, 1990.

[23] R. A. Krueger and M-A. Casey. Focus groups. 3rd Edition. A practical guide for applied research, Sage publications, Thousand Oaks California, 2000.

[24] P. Lindberg, M. Josephson, L. Alfredsson and E. Vingrd, Promoting excellent work ability and preventing poor work ability: The same determinants? Results from the Swedish HAKul study, Occup Environ Med. 63 (2006), 113-120.

[25] P. Lindberg and E.Vingård, De friska - en studie kring livsoch arbetsbetingelser som stödjer en positiv hälsoutveckling, [In Swedish]. (Healthy people - a study of health-supporting 
life and work conditions supporting a positive development of health), in: Handlingsplan för ökad hälsa i arbetslivet. Mål, ansvar och åtgärder från ett övergripande mål för människor $i$ arbete. Del 2. Bilagor. Eds, Socialdepartementet, 2002, pp. 241-300, (SOU 2002:5).

[26] G. S. Lowe, G. Schellenberg and H. S. Shannon, Correlates of employees' perceptions of a healthy work environment, $A m \mathrm{~J}$ Health Promot. 17 (2003), 390-399.

[27] J. P. Mackenbach, J. van den Bos, I. M. A. Joung, H. van de Mheen and K. Stronks, The determinants of excellent health: Different from the determinants of ill health? Int J Epidemiol. 23 (1994), 1273-1281.

[28] D. Morgan, Focus groups as qualitative research. Sage publications, London, 1997.

[29] P. Nilsson, I. H. Andersson, Å. Bringsén and G. Ejlertsson, Development and Quality Analysis of the Work Experience Measurement Scale (WEMS), WORK. 35 (2010), 153-161.

[30] K. Nilsson, A. Hertting, I-L. Petterson and T. Theorell, Pride and confidence at work: Potential factors of occupational health in a hospital setting, BMC Public Health. 5 (2005), 92.

[31] M. Polanyi, T. McIntosh and A. Kosny, Understanding and improving the health of workers in the new economy: A call for a participatory dialogue-based approach to work-health research, Crit PublicHealth. 15 (2005), 103-119.

[32] A. Robbins, J. Spence and H. Clark, Psychological Determinants of Health and Performance: The Tangled Webb of Desirable and Undesirable Characteristics, J Pers Soc Psychol. 61 (1991), 755-765.

[33] M. Rosenbaum, Self-control under stress: The role of learned resourcefulness, Adv Behav Res Ther. 11 (1989), 249-258.

[34] J. Siegrist, Adverse health effects of high-effort/low-reward conditions, J Occup Health Psychol. 1 (1996), 27-41.

[35] Socialdepartementet. Handlingsplan för ökad hälsa i arbetslivet. Mål, ansvar och åtgärder från ett övergripande $m l$ för människor i arbete. Del 1. Slutbetänkande, [In Swedish] (Action plan for improved health in working life. Purpose, responsibility and interventions from an overall perspective for people at work. Part 1. Concluding remarks) (SOU 2002:5). Stockholm: Statens Offentliga Utredningar, 2002.

[36] T. Theorell, New directions for psychosocial work environment research, Scand J Public Health. 34 (2006), 113-115.

[37] WHO. Constitution, WHO, New York, 1948.

[38] WHO. Ottawa Charter for Health Promotion, WHO, Copenhagen, 1986. 